
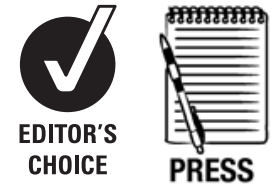

RELEASE

${ }^{1}$ Division of Population Health and Education, St George's, University of London, London, UK

${ }^{2}$ London Deanery, London, UK

\section{Correspondence to}

Dr Carwyn Hooper, St George's, University of London, Division of Population Health and Education, Cranmer Terrace, London SW17 ORE, UK; hoopercarwyn@googlemail. com

Received 11 July 2011 Revised 21 December 2011 Accepted 14 January 2012 Published Online First

7 March 2012

PAPER

\title{
Liberty or death; don't tread on me
}

\author{
Carwyn Hooper, ${ }^{1}$ John Spicer $^{2}$
}

\begin{abstract}
Many jurisdictions require cyclists to wear bicycle helmets. The UK is currently not one of these. However, an increasing number of interest groups, including the British Medical Association, want to change the status quo. They argue that mandatory cycle helmet laws will reduce the incidence of head injuries and that this will be both good for cyclists (because they will suffer fewer head injuries) and good for society (because the burden of having to treat cyclists suffering from head injuries will be reduced). In this paper we argue against this position. We suggest that cycle helmets may not be especially effective in reducing head injuries and we suggest that the imposition of such a restrictive law would violate people's freedom and reduce their autonomy. We also argue that those who accept such a restrictive law would be committed to supporting further legislation which would force many other groups - including pedestrians - to take fewer risks with their health. We conclude that cycle helmet legislation should not be enacted in the UK unless, perhaps, it is restricted to children.
\end{abstract}

\section{INTRODUCTION}

Governments have a habit of interfering with their citizens' rights to decide how much risk to take with their own health. In many countries, car drivers are prohibited from travelling without wearing seatbelts, motorbike riders are forbidden from riding without helmets, and the consumption of most recreational drugs is proscribed. The British government is no different in this regard, and it may now be turning its risk-averse eye towards cyclists who choose to cycle without helmets.

In 1998-1999, a private members' bill was put before the British parliament to make cycle helmets compulsory for children under $16 .{ }^{1}$ A similar bill was put before parliament in 2003-2004. ${ }^{1}$ Both bills failed. These failures may have had something to do with the unwillingness of the British Medical Association (BMA) to support such legislation; in 1999 the BMA published a report on cycling helmets in which they made clear their opposition to compulsory helmet use for cyclists. ${ }^{2}$ However, the BMA recently accomplished a complete volte-

Quote from BMA 2010 Report 'Promoting safe cycling'

'The BMA, as part of its policy to improve safe cycling, supports compulsory wearing of cycle helmets when cycling for children and adults. ${ }^{3}$ face. Their 2010 report on promoting safer cycling now clearly states that the organisation supports compulsory helmet legislation. ${ }^{3}$

Given this recent change of heart, there is now good reason to think that the current coalition government might revisit the idea of compulsory cycling helmets. This is especially true given that the Northern Ireland Assembly has recently voted in favour of a bill that would make the wearing of cycle helmets compulsory. ${ }^{4}$ Admittedly, David Cameron, the current British Prime Minister, does not always wear a cycle helmet, and Boris Johnston, the current Mayor of London, has openly declared his opposition to such legislation. ${ }^{5} 6$ However, it seems increasingly likely that legislation requiring British cyclists to wear protective headgear while riding bicycles will be enacted during the course of this parliament.

\section{Boris Johnston's attitude to cycle helmet legislation}

'The important thing is that we assess the risk, we make the decision, and be it on our own heads-or, in the case of my helmet, sometimes not. ${ }^{6}$

In this article we critically assess the arguments put forward in favour of enacting mandatory cycle helmet legislation and conclude that there are good reasons to oppose such a policy. Instead, we recommend that governments should provide cyclists with public health information about the potential benefits of wearing helmets while eschewing all legislation that would require cyclist to wear helmets.

We will not discuss the issue of mandatory helmet legislation for children in this paper, although we note that there may be a strong case for putting such legislation on the statue books, and we also note that governments in the Czech Republic, Iceland and Slovenia have introduced such measures. ${ }^{7-9}$ As the new BMA report suggests, the argument in favour of mandatory cycle helmets for children is strong because there is much evidence to suggest that cycle helmets are more effective in preventing head injuries in children than they are in adults. ${ }^{3}$ We would also add that younger children may not be mature enough to make their own autonomous decisions about whether to wear helmets and, consequently, mandatory helmet legislation may be warranted for children under the age of 16. 


\section{THE LEGISLATIVE BACKGROUND}

Compulsory bicycle helmet laws for adults currently exist in a number of countries, including New Zealand and Finland, and various states in the USA. ${ }^{10}$ Other countries limit the application of their cycle helmet laws to children. For example, the law applies to all children under 15 in Slovenia and Iceland and to all children under 18 in the Czech Republic. ${ }^{7-9}$ The Northern Ireland Assembly, meanwhile, looks set to pass the Cyclists (Protective Headgear) Bill in the near future. ${ }^{4}$ This bill will require children and adults to wear cycle helmets and will enable police officers to issue financial penalties for failing to abide by the law. ${ }^{4}$ As noted above, there have been two recent attempts to enact similar legislation in the British parliament, but these were defeated on both occasions. ${ }^{1}$

\section{THE EMPIRICAL EVIDENCE}

Those who argue in favour of mandatory cycle helmet laws invariably believe that cycle helmets reduce the risk of injuries to the skull and brain caused by impacts to the head. ${ }^{11}$ We agree that, if wearing cycle helmets did reduce the risk of head injures by a non-marginal amount, then there would be a strong, prima facia, ethical basis for mandating the use of cycle helmets. However, the evidence for the effectiveness of helmets is not as clear cut as many advocates of cycle helmet legislation seem to think.

Having a layer of protection around the skull is likely to provide some positive protection in some circumstances, and a number of case-control studies have suggested that there is a correlation between increased helmet use and a corresponding decrease in the rate of head injury. ${ }^{12-14}$ The new BMA report, for example, notes that helmets 'reduce the incidence and severity of head, brain and upper facial injury for all ages' ${ }^{3}$

However, a number of studies have disputed the claim that cycle helmets are beneficial, and other studies have questioned the effectiveness of helmets. ${ }^{15} 16$ Research carried out in Australia showed that $80 \%$ of cyclists who were killed and $80 \%$ of those who were seriously injured in cycling accidents were wearing helmets when they had their accidents. ${ }^{17}$ Moreover, the overall risk to cyclists-whether they wear helmets or not-is actually quite small. There were 17064 reported cycling casualties in 2008 in the UK, yet the number of fatalities (104) and the number of serious injuries (2606) were not large-especially when one considers the number of 'road miles' covered by cyclists in the UK ever year. ${ }^{18}$ Every death is, of course, a terrible tragedy, but we need to keep some kind of perspective on these matters, and it is worth bearing in mind that over 35000 people died of lung cancer alone in 2008 in the UK-a figure that dwarfs the deaths from cycling. ${ }^{19}$

There are a number of reasons why cycle helmets might not provide as much useful protection as it is commonly assumed. First, cycle helmets in their present form may not be capable of providing significant levels of protection to the skull or the brain. For comparison, motorcycle helmets are made from much tougher material and provide far more protection, although their weight would make cycling with them very difficult. Second, cycle helmets may work well when cyclists simply fall off their bikes-this is typically what happens when children are involved in bike accidents-but many cycling injuries involve impacts with other vehicles and it is less clear whether cycle helmets provide much protection in these situations. ${ }^{17}$ Indeed, the new BMA report concedes that helmets are more effective when 'a cyclist falls from a cycle without the involvement of other vehicles.'

Even if cycle helmets do provide a reasonable degree of protection, however, other factors might explain why they are not effective in reducing the overall level of head injuries and death. For example, there is a concern that car drivers take less care when manoeuvring around cyclists who wear helmets. Moreover, there is some evidence that cyclists who wear helmets may take more risks than cyclists who do not wear helmets. ${ }^{20}$ The new BMA report admits that this is a real possibility, but the report also notes that research carried out in Spain did not find evidence of 'strong risk compensation mechanism among helmeted cyclists. 3

Indirect evidence for the effectiveness of cycle helmets comes from studies that look at the effects of instituting mandatory cycle helmet laws in different jurisdictions. These studies show that legislation leads to an increased use of helmets and a decrease in head injuries. ${ }^{21}$ The natural inference to draw is that the increased use of helmets is the cause of the decreased incidence of head injuries, and, in the new BMA report, this is exactly the inference that is drawn. ${ }^{3}$ However, there is some countervailing evidence to suggest that the effect may be explained by the fact that legislation reduces the number of people who are willing to cycle. ${ }^{22}$

A large narrative review was carried out by the Cochrane Collaboration in 2009 with the aim of examining the effect of legislative changes in some states of the USA. They found that mandatory helmet legislation did increase the use of cycle helmets, and they also found that there was a decrease in head injury rates. However, the authors of the review accepted that "none of the studies measured actual bicycle use so it was not possible to evaluate the claim that fewer individuals were cycling due to the implementation of the helmet laws'. ${ }^{21}$ Thus the Cochrane review does not rule out the possibility that a decrease in reported head injuries might well be explained by a decrease in cycling activity.

It is worth noting that, even if cycle helmets did not reduce head injuries, they might still be effective in reducing the incidence of head injures because they would change the behaviour of cyclists. By the requirement to don protective helmets, cyclists are effectively reminded that cycling is a potentially dangerous activity and that they should take care when cycling. Analogously, the requirement to wear protective helmets on construction sites, even when the risk of being injured is small, may reduce head injuries because the helmet acts as a warning device which reminds people to take care. This argument may prove to be a powerful one, but we are not aware of any evidence that wearing helmets reduces risky behaviour, and, as we have argued above, wearing protective helmets may actually increase the risks to cyclists if it causes motorists to take fewer precautions when manoeuvring around cyclists.

\section{THE ETHICAL DEFENCE OF CYCLE HELMET LEGISLATION}

If cycle helmets reduce head and brain injuries by a non-marginal amount, there are two main ethical arguments in favour of forcing people to wear helmets when they cycle.

First, this could be done in the name of utility. If helmets reduce head and brain injuries, then there is a prima facia ethical reason to enact legislation to require people to wear them. The suffering experienced by people with moderate to severe brain injuries can be immense, and such injuries are often utterly devastating. Indeed, the magnitude of the harms caused may be considered so severe that they outweigh their relative rarity. Thus, any policy that reduced the incidence of such injuries ought to be considered seriously, given its likely impact on overall levels of utility. ${ }^{23}$ Importantly, this seems to be the primary argument deployed by the BMA in their 2010 report, 
even though the argument is not explicitly stated anywhere in the document. ${ }^{3}$

Second, governments could enact mandatory legislation on the grounds of justice. ${ }^{23}$ Citizens who gamble with their own health risk becoming a burden to other members of society if the cost of providing health is covered by the public purse and not by the individuals who take the risks. In so far as such 'free riding' behaviour is deemed to be unfair, the state may be entitled-and may even have a duty-to minimise its exposure to the cost of treating people with self-inflicted injuries by requiring people to reduce the risk of injuring themselves. One way of achieving such a goal in the context of cycling would be to require all cyclists to wear helmets.

\section{PROBLEMS WITH THE UTILITARIAN DEFENCE OF CYCLE HELMET LEGISLATION}

There are a number of normative and practical problems with the utilitarian argument in favour of mandatory cycle helmet legislation, and it is worth noting that the new BMA report barely makes any mention of these problems. The main normative issue is that such legislation is paternalistic and rides rough-shod over competent citizens' rights to decide how much risk to take with their own health. Paternalism certainly has its place where children are concerned, but where coercive legislation is intended for the sole benefit of competent adult citizens, this must give us significant pause.

Admittedly, where the risks of a certain activity are exceptionally high, even people who are normally implacably opposed to paternalism might deem it right and proper for the government to prevent people from engaging in these activities. For example, legislation requiring the mandatory of use of motorcycle helmets might be more justifiable than legislation requiring people to wear cycle helmets because the benefits in the former case are much more significant. A recent Cochrane review, for example, suggests that motorcycle helmets reduce the risk of head injury by around $69 \%$ and death by around $42 \%$, which suggests that motorcycle helmets are far more effective than cycle helmets in reducing the incidence of serious injury and death. ${ }^{24}$

Liberals opposed to paternalism might also concede that paternalism may be permissible if the freedom that is being overridden in the name of paternalism is not an important right. The right not to wear cycle helmets may not be considered an important right. However, we ought not to trivialise this right. Conceptually, the right not to wear helmets is part of a more general right to determine how much risk to take with our health, and this, more general, right is, we would argue, a very important right. Of course, not everyone will wish to take the same risks with their health, and many will think that the decision not to wear helmets is foolish. However, we all have a strong interest in having the freedom to take risks with our own health and this general right should, prima facia, be protected however it is expressed. It is also worth stressing that the right not to wear helmets is a negative right, and those who support the values of liberty and autonomy ought to feel especially wary of allowing the state to trammel over such rights.

Of course, there may be a limit to how much risk people should be allowed to take with their own health. Libertarians would not agree, but almost everyone else would argue that there is a threshold beyond which the risks one takes with one's own health becomes too great. As such, legislation that would prevent people from taking extreme risks might be justifiable. For example, it is possible to argue that the sale of heroin should be proscribed because of the serious harm that heroin can cause to those who consume the drug. Likewise, it is possible to argue that the risks involved with riding motorbikes without helmets is so egregious that mandatory helmet legislation is required to prevent people from taking the risk. Needless to say, it is very difficult to work out where the threshold should be 'set', even if most people are in agreement that there ought to be a threshold. We will not attempt to define the threshold here, but we would venture that the risk a cyclists assumes by not wearing a helmet is almost certainly too small to breach the threshold unless the bar is set so low that almost any activity will be deemed too risky to be tolerated.

There are also empirical problems with the utilitarian defence of mandatory cycle helmet laws. Forcing people to wear helmets will have negative as well as positive effects on utility. To begin with, such a law would increase the costs of cycling because everyone would be required to purchase a helmet. Cyclists with a libertarian bent will also be seriously aggrieved by such legislation, and many others will be moderately or mildly irritated. A substantial minority of cyclists might even prefer to give up cycling altogether than be forced to cycle with helmets. Of course, the resentment might have a short latency, as cyclists might adjust, over time, to a more restrictive national policy on their headgear in the same way that car occupants' resentment towards mandatory seatbelt legislation seems to have largely melted away over the last few decades. However, there can be no guarantee that this would happen, and the resistance to cycle helmet legislation might well be quite profound given the degree of hostility to such legislation that exists in some sections of the cycle community.

Whether the loss to utility from such considerations as these would outweigh the utility gained from the reduction in the prevalence of head injuries is not easy to determine, but we suggest that this is a real possibility, and we suggest that further empirical work ought to be conducted before legislation is put in place requiring people to wear helmets.

\section{OBJECTIONS TO THE JUSTICE DEFENCE OF CYCLE HELMET LEGISLATION}

There are also a number of empirical and normative problems with the argument from justice. From an empirical point of view, cyclists who refuse to wear helmets may not be a net burden on the health service. After all, as the BMA openly accepts, cycling is a health-enhancing activity, and, although some cyclists will need treatment for cycling-related injuries, most will be healthier, leaner and fitter as a consequence of cycling. ${ }^{3}$ Indeed, the health benefits of cycling outweigh the risks-perhaps by as much as a factor of 20 to $1 .^{25}$ Thus the argument that cyclists who take risks by not wearing a helmet are a net burden on the public purse may not hold any water.

From a normative point of view, many accounts of justice do not require people to 'pay the price' of their health-affecting choices. Indeed, many egalitarian and liberal accounts of justice would regard any attempt to force people to bear the costs of their health-affecting behaviour as a moral travesty. ${ }^{26}$ Anderson, for example, argues that cost bearing is not only inhumane but also violates the principles of democratic equality. ${ }^{26}$

Of course, some accounts of justice accept the permissibility of forcing people to bear the burden of their health-affecting choices, and some even require that the state ensure that people bear the costs of their choices. ${ }^{27}$ Luck egalitarians, in particular, would defend the idea that costs ought to be borne by those who voluntarily chose to engage in them. ${ }^{27}$ However, even those who defend a luck egalitarian account of justice accept the general dictum of justice that like cases should be treated alike. Thus, if cyclists are going to be forced to take fewer risks, then, 
in the name of consistency and fairness, everyone ought to be required to reduce the comparable risks they run in other aspects of their lives. For example, skiers, skateboarders, sky divers, car occupants and even pedestrians might all be required to wear helmets too. ${ }^{28} 29$ In fact, people practising some of these other pursuits could even, by extension, be coerced into wearing spine protectors and other protective devices relevant to the nature of the activity.

Of course, attempting to reduce the comparable risks that people run is often neither practically nor politically possible. It is much easier to reduce the risks that people run in some areas of life (eg, forcing car occupants to wear seatbelts) than it is in others (eg, preventing people from engaging in unprotected sex) for a myriad of different reasons. Nonetheless, it is unclear how politically feasible it would be to require cyclists to wear helmets given the degree of hostility to mandatory helmet legislation that exists in the cycling community.

\section{POLICY RECOMMENDATIONS AND CONCLUSION}

We agree with the BMA that governments around the world should continue to provide public health information to their citizens to inform them about the potential benefits of wearing cycle helmets. However, we disagree with the BMA in so far as we think that governments should resist the temptation to enact legislation that requires adults to wear cycle helmets. We do not advocate the strong libertarian claim encapsulated in the American refrain 'Liberty or death; don't tread on me'. Indeed, we entirely accept that governments have a role to play that goes above and beyond the requirements of the minimal state. However, we cannot support legislation that would require competent adults to wear cycle helmets, particularly given the lack of evidence regarding the effectiveness of cycle helmets and given the importance of defending people's right to take risks with their health. If competent adults wish to cycle with their hair (or their shiny pates) exposed to the wind, rain and sky, then they ought to be able to so without interference from the government or from anyone else.

Competing interests None.

Provenance and peer review Not commissioned; externally peer reviewed.

\section{REFERENCES}

1. Parliamentary Transport Council for Transport Safety. Report PB05/04. 2004. http://www.pacts.org.uk/docs/pdf-bank/cyclehelmets.pdf (accessed 22 Mar 2011).
2. British Medical Association. Cycle Helmets. London: British Medical Association, 1999.

3. British Medical Association. Promoting Safe Cycling. London: British Medical Association, 2010

4. Northern Ireland Assembly. 2010. http://www.niassembly.gov.uk/legislation/ primary/2010/nia9 10.htm (accessed 25 Mar 2011).

5. London Evening Standard. David Cameron Under Fire for Not Wearing a Cycle Helmet. 2010. http://www.thisislondon.co.uk/standard/politics/article-23822074david-cameron-under-fire-for-not-wearing-a-helmet.do (accessed 25 Mar 2011)

6. Johnston B. Get a Bike Helmet to Get Ahead —or May be Not. The Telegraph. 2008 http://www.telegraph.co.uk/comment/columnists/borisjohnson/3559551/Get-a-bikehelmet-to-get-ahead-or-maybe-not.html (accessed 10 Mar 2011).

7. Bicycle Helmet Research Foundation. Helmet Laws: Czech Republic. http:// www.cyclehelmets.org/1110.html (accessed 10 Mar 2011).

8. Bicycle Helmet Research Foundation. Helmet Laws Iceland. http://cyclehelmets. org/1124.html (accessed 25 Feb 2011).

9. Bicycle Helmet Research Foundation. Slovenia Drops Plans for Adult Helmet Law. 2010. http://www.cyclehelmets.org/1207.html?NKey=7 (accessed 10 Mar 2011).

10. Bicycle Helmet Safety Institute. Helmet Laws for Bicycle Riders. http://www helmets.org/mandator.htm\#international (accessed 25 Feb 2011).

11. Department for Transport. Bicycle Helmets: Review of the Effectiveness (No. 30). London: Department for Transport, 2004.

12. Thompson RS, Rivara FP, Thompson DC. A case control study of the effectiveness of bicycle safety helmets. N Engl J Med 1989;320:1361-7.

13. Thompson DC, Rivara FP, Thompson RS. Effectiveness of bicycle safety helmets in preventing head injuries: a case-control study. JAMA 1996;276:1968-73.

14. Cook A, Sheikh A. Trends in serious head injuries among English Cyclists and pedestrians. Inj Prev 2003;9:266-7.

15. Burdett A. Helmet Effect Undetectable in Fatality Trends. http://www. vehicularcyclist.com/fatals.html (accessed 10 Jun 2011).

16. Kunich T. Latest CPSC Helmet Standard and US Fatality Trends. http://www. vehicularcyclist.com/kunich.html (accessed 20 Jun 2011).

17. Thomas S, Acton C, Nixon J, et al. Effectiveness of bicycle helmets in preventing head injury in children: case-control study. BMJ 1994;308:173-6.

18. Department for Transport. Reported Road Casualties Great Britain: 2009 Annual Report. London: The Stationery Office, 2010. http://www.dft.gov.uk/adobepdf/ 162469/221412/221549/227755/rrcgb2009.pdf (accessed 13 Feb 2011).

19. Cancer Research UK. Lung Cancer and Smoking Statistics - Key Facts. http://info. cancerresearchuk.org/cancerstats/keyfacts/lung-cancer/ (accessed 10 Jun 2011).

20. Hilman M. Cycle Helmets - The Case for and Against Them. London: Policy Studies Institute, 1993.

21. Macpherson A, Spinks A. Bicycle helmet legislation for the uptake of helmet use and prevention of head injuries (Review). Cochrane Database Syst Rev 2008;(3): CD005401.

22. Robinson DL. Head injuries and bicycle helmet laws. Accid Anal Prev 1996;28:463-75

23. Sheik A, Cook A, Ashcroft R. Making cycle helmets compulsory: ethical arguments for legislation. J R Soc Med 2004:97:262-5.

24. Liu BC, Ivers R, Norton R, et al. Helmets for preventing injury in motorcycle riders. Cochrane Database Syst Rev 2008;(1):CD004333.

25. Hillman M. Cycling and the promotion of health. PTRC 20th Summer Annual Meeting. Proceedings of Seminar B 1992;1:25-36.

26. Anderson E. What is the point of equality? Ethics 1999;109:287-302

27. Segall S. Health, Luck and Justice. Princeton: Princeton University Press, 2010.

28. Unwin NC. Cycle helmets-when is legislation justified? J Med Ethics 1996:22:41-5

29. Carnall D. Cycle helmets should not be compulsory. BMJ 1999;318:1505-6. 